Syntax Literate : Jurnal Ilmiah Indonesia p-ISSN: 2541-0849

e-ISSN : 2548-1398

Vol. 6, No. 3, Maret 2021

\title{
ANALISIS PENDIDIKAN KARAKTER YANG BERBASIS NILAI-NILAI PANCASILA DI SMP IT TAZKIA INSANI MAJALENGKA
}

\section{Ujang Permana}

Sekolah Tinggi Ilmu Kesehatan (STIKes) YPIB Majalengka, Indonesia

Email: ujangpermana1974@gmail.com

\section{Abstract}

The purpose of this study is to describe and analyze the planning, implementation, assessment and obstacles and solutions carried out in the implementation of character education based on pancasila values at SMPIT Tazkia Insani Majalengka. This type of research is descriptive qualitative research with a case study approach to determine the implementation of character education based on Pancasila values at SMPIT Tazkia Insani Majalengka. The results of the study include, among others, (1) The learning planning made by teachers is in accordance with the principles of planning in curriculum 2013 that contains KI, $K D$, Indicators, characters to be achieved, general objectives of learning, media, resources and approaches or methods of supporting learning, learning scenarios and authentic assessment. (2) The implementation of the planting of character values in SMPIT Tazkia Insani Majalengka in accordance with the values of Pancasila has been planned in the RPP. 3) Assessment of learning conducted by teachers by assessing attitudes through the scale of attitudes and aspects of skills (psychomotor). (4) Solutions made in overcoming obstacles derived from teachers with teacher participation in curriculum training 2013, participation in Teacher Consultation Subjects (MGMP), mentoring the utilization of IT in learning, for obstacles from students are carried out by psychological approach through habituation, civility, activeness in extracurricular activities, rewarding and punishment, to inhibit the lack of face-to-face hours by working with other mapel teachers in sharpening character values.

Keywords: character education; pancasila values
Abstrak
Tujuan dalam penelitian ini adalah untuk mendeskripsikan dan menganalisis perencanaan, pelaksanaan, penilaian serta hambatan dan solusi yang dilakukan dalam pelaksanaan pendidikan karakter berbasis nilai-nilai Pancasila di SMPIT Tazkia Insani Majalengka. Jenis penelitian ini adalah penelitian kualitatif deskriptif dengan pendekatan study kasus untuk mengetahui pelaksanaan pendidikan karakter yang berbasis nilai-nilai Pancasila di SMPIT Tazkia Insani Majalengka. Hasil penelitian antara lain; (1) Perencanaan pembelajaran yang dibuat guru telah sesuai dengan prinsip perencanaan dalam Kurikulum 2013 yang memuat KI, KD, Indikator, karakter yang hendak dicapai, tujuan umum pembelajaran, media, sumber dan pendekatan atau metode pendukung pembelajaran, scenario pembelajaran serta authentic assessment; (2) Pelaksanaan penanaman nilai-nilai 
karakter di SMPIT Tazkia Insani Majalengka sesuai dengan nilai-nilai Pancasila telah direncanakan dalam RPP; (3) Penilaian pembelajaran yang dilakukan guru dengan menilai sikap melalui skala sikap dan aspek ketrampilan (psikomotorik); (4) Solusi yang dilakukan dalam mengatasi hambatan yang berasal dari guru dengan keikutsertaan guru dalam Diklat Kurikulum 2013, keikutsertaan dalam Musyawarah Guru Mata Pelajaran (MGMP), pendampingan pemanfaatan IT dalam pembelajaran, untuk hambatan dari siswa dilakukan dengan pendekatan psikologis melalui pembiasaan, keteladanan, keaktifan dalam kegiatan ekstrakurikuler, pemberian reward dan punishment, untuk hambatan kurangnya jam tatap muka dengan bekerja sama dengan guru mapel lain dalam penajaman nilai-nilai karakter. Penelitian ini diharapkan menjadi sumbangan pemikiran bagi pengembangan ilmu pengetahuan dalam bidang pendidikan mengenai pelaksanaan pendidikan karakter yang berbasis nilai-nilai Pancasila di SMP.

Kata kunci: pendidikan karakter; nilai-nilai pancasila

Coresponden Author

Email: ujangpermana1974@gmail.com Artikel dengan akses terbuka dibawah lisensi

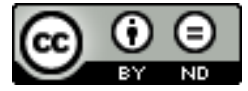

\section{Pendahuluan}

Pendidikan adalah sarana untuk mencerdaskan bangsa dan menjadi pilar untuk mengentaskan kemiskinan pengetahuan, menuntaskan persoalan kebodohan dan menyelesaikan berbagai persoalan bangsa. Pendidikan tidak terbatas pada proses yang berlangsung di dalam lingkungan sekolah semata. Pendidikan merupakan suatu aktivitas sosial yang esensial (Somantri, 2014).

Pada masyarakat modern, fungsi pendidikan berkembang menjadi proses spesialisasi dan melembaga yang berbentuk pendidikan formal, tetapi masih terintegrasi dengan proses pendidikan informal di luar sekolah. Dalam Undang-Undang Nomor 20 Tahun 2003 tentang sistem pendidikan nasional pasal 3 menyatakan bahwa: Pendidikan nasional berfungsi mengembangkan kemampuan dan membantu watak serta peradaban bangsa bermartabat dalam rangka mencerdaskan kehidupan bangsa, bertujuan berkembangnya potensi siswa agar menjadi manusia yang beriman dan bertaqwa kepada Tuhan Yang Maha Esa, berakhlak mulia, sehat berilmu, cakap, kreatif, mandiri, dan menjadi warga negara yang demokratis serta bertanggung jawab (Nasional, 2003).

Tetapi kenyataan yang terjadi di masyarakat hingga saat ini kerap kita temukan bahwasannya dalam satu sisi pendidikan mampu mencetak para ilmuan dan cendekiawan, akan tetapi di sisi lain sering kita temui realitas yang belum berhasil membentuk generasi yang memiliki karakter akhlak mulia, terbukti dengan masih banyaknya degradasi moral yang terjadi di tengah masyarakat. Bahkan belum lama ini publik dikejutkan dengan ramainya aksi anarkis di kalangan siswa sekolah dasar, mulai kasus penyalahgunaan narkoba, perkelahian, pemerkosaan sampai dengan pencabulan. Beragam perilaku buruk itu tentu saja sangat dipengaruhi oleh derasnya arus modern 
yang merusak tatanan nilai karakter bangsa ini. Karena itu, hal yang sangat urgent bagi para pendidik di negeri ini untuk bersama-sama membangun pendidikan karakter siswa agar mereka dapat menghadapi berbagai tantangan pendidikan masa depan.

Dengan adanya pendidikan karakter bangsa di sekolah maka diharapkan terbangun masyarakat yang berkarakter baik, dan mempunyai norma-norma yang menjadi dasar kehidupan bersama. Pendidikan karakter melahirkan wujud trust (kepercayaan) di masyarakat sehingga membangun hubungan saling mempercayai di berbagai aspek kehidupan. (Zainun, 2015) mengatakan, pendidikan karakter merupakan sebuah sistem penanaman nilai-nilai (karakter) bagi warga sekolah dengan menciptakan pengetahuan, kesadaran atau kemauan, dan tindakan dalam melaksanakan nilai-nilai, baik terhadap Tuhan Yang Maha Esa (TYME), untuk diri sendiri, pada sesama lingkungan, juga bersifat kebangsaan sehingga menciptakan insan yang kamil.

Pendidikan karakter yang diterapkan di sekolah bisa dikemas dalam program pembelajaran di setiap mata pelajaran. Silabus pembelajaran yang berhubungan dengan nilai-nilai karakter atau norma di setiap mata ajar bisa dikembangkan serta integrasikan dengan kehidupan keseharian. Sehingga proses pembelajaran nilai-nilai karakter tak terbatas dalam tataran kognitif semata akan tetapi bisa menyentuh pada kehidupan internal peserta didik juga dikaitkan dengan pengalaman di kehidupan nyata siswa baik di dalam keluarga, sekolah ataupun di tengah-tengah masyarakat (Idris, 2017).

Sementara itu, proses penanaman nilai-nilai Pancasila untuk generasi sangatlah mendesak dilakukan sebab generasi bangsa ini harus berada di garis terdepan untuk mengantisipasi berbagai paham maupun budaya yang bersebrangan dengan Pancasila sehingga berpengaruh pada baik buruknya prilaku mereka di masa yang akan dating (Sayektiningsih, Sumardjoko, \& Muhibin, 2017).

Dalam observasi awal, peneliti memperoleh sebuah konsep pelaksanaan pendidikan karakter yang berhubungan dengan nilai-nilai Pancasila yang ada di SMPIT Tazkia Insani. Sekolah ini menyusun beberapa program di antaranya penanaman jiwa nasionalisme, membangun integritas, sifat gotong royong, membangun kemandirian serta menanamkan nilai-nilai religius dengan kurikulum yang digunakan yakni Kurikulum 2013.

Berdasarkan uraian latar belakang masalah di atas, maka peneliti tertarik untuk melaksanakan penelitian tentang Analisis Pendidikan Karakter yang Berbasis Nilai-nilai Pancasila di SMP IT Tazkia Insani Majalengka.

\section{Metode Penelitian}

Jenis penelitian ini adalah penelitian kualitatif deskriptif dengan pendekatan study kasus untuk mengetahui pelaksanaan pendidikan karakter yang berbasis nilai-nilai pancasila di SMPIT Tazkia Insani Majalengka (Creswell \& Creswell, 2017). Jenis dan sumber data dalam penelitian ini adalah data hasil pengamatan dan wawancara yang berkaitan dengan pendidikan karakter yang berbasis nilai-nilai Pancasila di SMP IT Tazkia Insani Majalengka. 


\section{Hasil dan Pembahasan}

\section{Perencanaan Penerapan Pendidikan Karakter yang Berbasis Nilai-Nilai Pancasila di SMPIT Tazkia Insani Majalengka.}

Berdasarkan pengamatan dokumen, penerapan pendidikan karakter yang berbasis nilai-nilai pancasila termuat dalam Rencana Pembelajaran (RPP) di SMPIT Tazkia Insani Majalengka yang masuk dalam berbagai unsur yang sesuai dengan pedoman penyusunan RPP di antaranya dalam rencana pembelajaran, yaitu standar kompetensi, kompetensi inti, kompetensi dasar, indikator, materi pokok, skenario pembelajaran, sumber, media pembelajaran, dan penilaian hasil belajar.

Sedangkan berdasarkan pengamatan peneliti di lapangan, guru SMPIT Tazkia Insani Majalengka telah melaksanakan perencanaan pembelajaran dengan menyusun RPP di bawah pengawasan oleh Kepala SMPIT Tazkia Insani Majalengka. Temuan ini relevan dengan hasil penelitian (Williams \& Megawangi, 2010) bahwa pendidikan karakter bisa diterapkan dengan beragam jenis mata pelajaran. Penerapan pendidikan karakter di berbagai mata pelajaran diterapkan dengan menghubungkan penerapan pendidikan karakter pada pembelajaran yang berbasis standar. Dalam hal ini, sangat bergantung pada luas tidaknya wawasan serta pandangan guru mata pelajaran dalam menyusun perencanaan pembelajaran.

Dalam penelitian ini ditemukan bahwasannya penyusunan RPP dilaksanakan secara bersama-sama baik dengan guru sejenis (PPKn) maupun guru mata pelajaran lainnya. Untuk memaksimalkan hasil perencanaan maka guru-guru di sekolah ini kerapkali mengambil referensi dari internet baik dalam proses perbaikan maupun penyesuaian agar pada pelaksananya dapat berlangsung secara efektif dan efisien. Sehingga dapat dikatakan, pada perencanaan pembelajaran, guru-guru di SMPIT Tazkia Insani Majalengka telah berupaya menyusun perencanaan untuk menanamkan beberapa nilai-nilai karakter yang sesuai dengan isi Kurikulum 2013 dengan baik.

Pelaksanaan pendidikan karakter berbasis nilai-nilai pancasila di SMPIT Tazkia Insani Majalengka. Berdasarkan hasil pengamatan di kelas maupun hasil wawancara (interview) dengan guru SMPIT Tazkia Insani Majalengka diketahui bahawa penerapan pendidikan karakter di sekolah ini dilaksanakan melalui berbagai kegiatan baik intrakurikuler maupun ekstrakurikuler (Ilmi, 2015).

Dalam kegiatan intra kurikuler (Lestari, 2016), sekolah ini mengintegrasikan nilai-nilai karakter di setiap materi pembelajaran sesuai dengan RPP yang telah disusun sebelumnya dengan pendekatan discovery learning atau inquiri (Balım, 2009). Penerapan nilai-nilai karakter dalam aktivitas pembelajaran di dalam kelas juga dilaksanakan dalam diskusi kelompok.

Penerapan nilai-nilai karakter di SMPIT Tazkia Insani Majalengka juga dilaksanakan di berbagai aktivitas pembiasaan seperti pada kegiatan apel pagi, membiasakan berjabat tangan dan mengucapkan salam, sholat wajib dan sholat sunah yang dilaksanakan secara berjamaah, kegiatan tadarus dan tahfidz (Baroroh, 2011). Menanamkan nilai-nilai karakter juga dilaksanakan pada Peringatan Hari 
Besar Nasional (PHBI). Selain itu, penerapan nilai-nilai karakter juga diterapkan dalam berbagai kegiatan ekstrakurikuler.

Berdasarkan temuan peneliti, kemampuan guru dalam pelaksanaan penerapan nilai-nilai karakter dalam pembelajaran telah sesuai dengan pedoman sehingga proses pembelajaran dapat terlaksana dengan baik dan sistematis mulai dari awal hingga akhir kegiatan. Guru juga kreatif menggunakan media pembelajaran sehingga suasana pembelajaran berlangsung dengan antusias. Setiap siswa juga aktif bertukar pikiran dan guru kerap memberikan stimulus agar siswa aktif bertanya serta mengungkapkan pendapat maupun pemikirannya.

Berdasarkan dokumentasi dalam penelitian ini, nilai-nilai karakter yang dikembangkan di SMPIT Tazkia Insani Majalengka yang berdasarkan nilai-nilai Pancasila terdiri dari 13 nilai karakter. Di antaranya nilai religius, nilai jujur, nilai toleran, nilai disiplin, nilai mandiri, nilai demokratis, nilai rasa ingin tahu, nilai semangat kebangsaan, nilai menghargai prestasi, nilai cinta damai, nilai gemar membaca, nilai peduli lingkungan serta nilai peduli sosial. Secara keseluruhan penerapan pendidikan karakter yang diselenggarakan di sekolah ini telah sesuai dengan nilai-nilai Pancasila, dengan mengintegrasikan nilai-nilai karakter di setiap materi pembelajaran, baik dalam pembelajaran di dalam kelas maupun kegiatan di lingkungan SMPIT Tazkia Insani Majalengka, baik dalam bentuk kegiatan pembiasaan maupun kegiatan ekstra kurikuler.

Langkah-langkah dalam mengintegrasikan nilai-nilai karakter di setiap materi pembelajaran sesuai dengan hasil penelitian yang dilaksanakan oleh pertama, (Komalasari \& Saripudin, 2017) bahwa model pembelajaran dilakukan berupa integrasi kontekstual strategi belajar dengan nilai-nilai hidup. Konsep ini dikembangkan agar membangun perasaan moral dan perilaku moral, sehingga peserta didik dapat memahami nilai-nilai hidup juga bisa menginternalisasikannya dalam kehidupan sehari-hari sebagai bagian dari keluarga maupun sebagai warga masyarakat atau bangsa.

Konsep penerapan pendidikan karakter di sekolah ini juga sejalan dengan penelitian yang dilakukan oleh (Cha, 2013) yang menyebutkan bahwa penanaman karakter peserta didik menjadi strategi utama melalui kompetensi karakter yang dilakukan bertahap dan diintegrasikan dalam subjek pengetahuan semua mata pelajaran.

\section{Penilaian Pendidikan Karakter Berbasis Nilai-Nilai Pancasila di SMPIT Tazkia Insani Majalengka}

Penerapan pendidikan karakter juga tidak terlepas dari penilaian pembelajaran Pendidikan Pancasila dan Kewarganegaraan (PPKn) yang dilaksanakan di SMP IT Tazkia Insani Majalengka. Penerapan pendidikan karakter berdampak serius pada penilaian kemampuan akademik peserta didik juga dapat dinilai pada sikap atau perilaku peserta didik di lingkungan sekolah maupun di lingkungan luar sekolah. Pendidikan karakter juga memberikan dampak positif dalam membangun 
lingkungan yang baik dan mendukung perkembangan iklim sekolah, dapat meningkatkan kerja sama yang positif guru dengan siswa sehingga terbangun situasi yang kondusif dalam aktifitas pembelajaran.

Sesuai hasil pengamatan (observasi) di kelas dan wawancara (interview) dengan guru dan siswa, peneliti mendapat temuan pelaksanaan penilaian yang sesuai dengan pedoman dan bersifat objektif. Berbagai aspek yang mendapat penilaian juga relevan dengan standar penilaian yakni penilaian aspek kognitif, aspek psikomotorik, dan aspek afektif pada peserta didik.

Hasil penelitian ini sesuai dengan teori (Maksudin, 2013) bahwa pendidikan nilai moral (karakter) bisa tercapai dengan baik dan optimal jika diiringi dengan nilai-nilai yang ditanamkan melalui praktik-praktik hidup siswa itu sendiri. Sehingga penilaian atas keberhasilan penerapan pendidikan karakter tidak hanya diukur dari penilaian kognitif semata namun juga dalam praktek keseharian. Tolak ukur praktek keseharian dapat dilihat dari kegiatan pembiasaan, kegiatan ekstrakurikuler, dan sikap perilakunya dalam kegiatan belajar mengajar.

Solusi mengatasi hambatan atau kendala yang dihadapi dalam penerapan pendidikan karakter berbasis nilai-nilai pancasila di SMPIT Tazkia Insani Majalengka. Sesuai hasil wawancara dengan Kepala SMPIT serta guru juga dokumen yang ada di SMPIT Tazkia Insani Majalengka diperoleh temuan bahwa dalam menghadapi hambatan penerapan pendidikan karakter berbasis nilai-nilai Pancasila di SMP IT Tazkia Insani Majalengka diselesaikan secara bersama-sama. Untuk menghadapi hambatan yang berasal dari guru maka pihak sekolah mengikutsertakan guru mapel dalam Diklat Kurikulum 2013 yang disertai pendampingan penguasaan IT. Sedangkan dalam menghadapi hambatan dari siswa maka pihak sekolah terus berupaya secara berkesinambungan melakukan pendekatan psikologis baik melalui program pembiasaan, keteladanan, bimbingan dan pendampingan.

\section{Kesimpulan}

Perencanaan Penerapan Pendidikan Karakter yang Berbasis Nilai-Nilai Pancasila di SMPIT Tazkia Insani Majalengka. Berdasarkan pengamatan dokumen, penerapan pendidikan karakter yang berbasis nilai-nilai pancasila termuat dalam Rencana Pembelajaran (RPP) di SMPIT Tazkia Insani Majalengka yang masuk dalam berbagai unsur yang sesuai dengan pedoman penyusunan RPP. Pelaksanaan Pendidikan Karakter Berbasis Nilai-Nilai Pancasila di SMPIT Tazkia Insani Majalengka. Berdasarkan hasil pengamatan di kelas maupun hasil wawancara (interview), penerapan pendidikan karakter di sekolah ini dilaksanakan melalui berbagai kegiatan baik intrakurikuler maupun ekstrakurikuler. Penilaian Pendidikan Karakter Berbasis Nilai-Nilai Pancasila di SMPIT Tazkia Insani Majalengka. Sesuai hasil pengamatan (observasi) di kelas dan wawancara (interview) dengan guru dan siswa, peneliti mendapat temuan pelaksanaan penilaian yang sesuai dengan pedoman dan bersifat objektif. Berbagai aspek yang mendapat penilaian juga relevan dengan standar penilaian yakni penilaian aspek 
kognitif, aspek psikomotorik, dan aspek afektif pada peserta didik. Solusi Mengatasi Hambatan atau Kendala yang Dihadapi dalam Penerapan Pendidikan Karakter Berbasis Nilai-Nilai Pancasila di SMPIT Tazkia Insani Majalengka. Solusi mengatasi hambatan atau kendala yang dihadapi dalam penerapan pendidikan karakter berbasis nilai-nilai Pancasila di SMPIT Tazkia Insani Majalengka dilakukan secara bersama-sama dan secara berkesinambungan melakukan pendekatan psikologis baik melalui program pembiasaan, keteladanan, bimbingan dan pendampingan. 


\section{BIBLIOGRAFI}

Balım, Ali Günay. (2009). The Effects of Discovery Learning on Students' Success and Inquiry Learning Skills. Eurasian Journal of Educational Research (EJER), (35).

Baroroh, Kiromim. (2011). Upaya meningkatkan nilai-nilai karakter peserta didik melalui penerapan metode role playing. Jurnal Ekonomi Dan Pendidikan, 8(2).

Cha, Sung Hyun. (2013). Restructuring the concept of character education and policy in Korea. KEDI Journal of Educational Policy, 10(3).

Creswell, John W., \& Creswell, J. David. (2017). Research design: Qualitative, quantitative, and mixed methods approaches. Sage publications.

Idris, Saifullah. (2017). Internalisasi Nilai dalam Pendidikan (Konsep dan Kerangka Pembelajaran dalam Pendidikan Islam). Darussalam Publishing.

Ilmi, Darul. (2015). Pendidikan karakter berbasis nilai-nilai kearifan lokal melalui ungkapan bijak Minangkabau. ISLAM REALITAS: Journal of Islamic \& Social Studies, 1(1).

Komalasari, Kokom, \& Saripudin, Didin. (2017). Pendidikan karakter konsep dan aplikasi living values education. Bandung: Refika Aditama.

Lestari, Prawidya. (2016). Membangun karakter siswa melalui kegiatan intrakurikuler, ekstrakurikuler, dan hidden curriculum di sd budi mulia dua pandeansari yogyakarta. Jurnal Penelitian, 10(1), 71-96.

Maksudin, Maksudin. (2013). Pendidikan Karakter Nondikotomik (Upaya Membangun Bangsa Indonesia Seutuhnya). Jurnal Pendidikan Karakter, (2), 120852.

Nasional, Departemen Pendidikan. (2003). Undang-Undang Nomor 20 Tahun 2003 Tentang Sistem Pendidikan Nasional. Jakarta: Depdiknas, 33.

Sayektiningsih, Sumardjoko, Sumardjoko, Bambang, \& Muhibin, Achmad. (2017). Penanaman Nilai-Nilai Karakter dalam Pembelajaran Pendidikan Pancasila dan Kewarganegaraan di Madrasah Aliyah Muhammadiyah Klaten. Manajemen Pendidikan, 12(3), 228-238.

Somantri, Manap. (2014). Perencanaan pendidikan. PT Penerbit IPB Press.

Williams, Russell T., \& Megawangi, Ratna. (2010). Kecerdasan plus karakter. Tersedia: Http://Ihf-Org. Tripod. Com.

Zainun, Aqib. (2015). Pendidikan Karakter Suatu Sistem penanaman Nilai. Pustaka Pelajar, Yogyakarta. 